\title{
Effect of Retrofitting on Beam-Column Joints
}

\author{
Deependra Prashad Bhatta, Sandeep Singla, Manish Kaushal, Anuj Sachar
}

\begin{abstract}
During the serviceable life of R.C.C structures they are found to show evidence of distress due to various reasons. To bring such structures back to their functional/serviceable condition these structures need urgent attention and enquiry for finding out reasons of distress along with appropriate remedial treatments so as to increase serviceable life of such structures and bring them back to their functional use. So the process of retrofitting involves upgrading and enhancing the strength of deficient structures and their components. Safety of life is a priority issue to be addressed in process of retrofitting. For preventing injury and death of occupants and for preventing damage to structural components and collapse of structure as a whole, some retrofitting techniques try to deal with the issue to avoid damage. As a retrofitting technique, ferrocement technique is one of commonly used procedure of improving strength which is due to their good durability, less cost, easy availability and ease in application with requirement of intricate formwork. Application of ferrocement can be quickly done on the damaged structural elements without any requirements of chemical bonding agents. Also the ferrocement application requires less skill labour in comparison to other retrofit solutions available these days. Ferrocement is light in weight, easy to construct \& have low self weight which is why it is preferred to other techniques of retrofitting. It has higher tensile strength then R.C.C. Also the thickness of ferrocement is a fraction of thickness of R.C.C. structural elements which makes it a complementary material for prefabricated structures. In the present study six R.C.C. Beam column joint specimens were casted. Two controlled specimens were initially stressed to ultimate load (100\% damage) and other four specimens are stressed to prefixed percentages of ultimate load. All six specimens were then retrofitted using ferrocement for upgrading the strength of Beam column joints in flexure and shear. Chicken wire mesh is wrapped all around the specimen. From the study it is observed that retrofitted specimens has shown considerable decrease in deflection if we compare them to controlled specimens. Also the percentage decrease in deflection for specimens subjected to $75 \%$ and $50 \%$ of ultimate loads is considerably higher to those specimens which are subjected to $100 \%$ damage i.e. ultimate load.
\end{abstract}

Keywords- Retrofitting, Beam-column joint, bond, development length, jacketing, Wire mesh, deflection, shear, ferrocement.

Abbreviations:-

R.C.C- Reinforced Cement Concrete

CFRP- Carbon Fiber Reinforced Polymers

\section{INTRODUCTION}

Before the extensive research on retrofitting and special design features of seismically stable structures, very less considerations was given to special detailing of seismic

Deependra Prashad Bhatta, M.Tech Scholar, Civil Engineering, RIMT University, Punjab, India

Sandeep Singla, Civil Engineering, RIMT University, Punjab, India Manish Kaushal, Civil Engineering, RIMT University, Punjab, India Anuj Sachar, Civil Engineering, RIMT University, Punjab, India design. Various structural elements are retrofitted depending upon lack of strength parameters in the element. Shear wall nowadays are built at ground floors of building to resist lateral shear/base shear. Injection of grouts in cracks bonding of roof wall connections, strength upgrading of foundations are included retrofitting measures. Replacement of existing elements and addition of new elements of same material or composite materials also comes under the category of retrofitting. Seismic detailing, various materials used ,structural pattern of failure, load resisting elements system are the factors to be kept in consideration for deciding methodology of retrofitting. Retrofitting involves increasing the strength of structure laterally. Additional elements can also be provided. Alteration in properties of concrete is difficult after its setting. Intensive care should be taken while casting of concrete. Need of retrofitting also occurs because of revision of codes from time to time. Structure may need retrofitting if it is damaged after earthquake or if it initial design of structure was not done considering the detailing as per seismic codes. Approach of strong column weak beam is also followed as a retrofitting strategy. In R.CC structures beam-column junctions are most important load transfer and resisting members. These junctions are susceptible to get damaged and deteriorated during seismic activity. So retrofitting of beam-column joints is very important. Seismic zone of some areas get upgraded which necessitates up gradation of seismic strength of structures in those areas. Corner rebars are incorporated at beam column junction for strengthening. Beam column joints have designed load resisting capacity. Joints get damaged when they are subjected to loads higher than their designed capacity. Moments and rotations are induced in beam column junctions when they are subjected to loads. Rigidity of beam column junctions are taken into account while we analyze these joints. In present design practice in our country, beam-column joints are uncared for precise design with interest being constrained to provision of enough anchorage for main reinforcement of beam. Above design practice is fine if seismic loads are not expected to be acted upon structure. Unhealthy design and detailing of joints in structures have shown disastrous failures earlier. Broad investigations are being carried in previous decades regarding the seismic response of the joints. Codal up gradations are done to include the changes observed as a result of various investigations. Some structures which were designed and constructed by earlier versions of codes were extensively susceptible to damages due to seismic activity. But adjustments to their structural constitution and arrangement have shown improvements to their seismic behavior. These types of observation results regarding better performance of retrofitted buildings under seismic loads had elevated the confidence among the 
construction engineers and builders to carry out retrofitting and modifications of seismically inferior buildings and structures rather than demolishing them and rebuilding. During the design of beam column junction to resist earthquake loads, it is enviable to restrict the strength degradation of joint up till the point when beam reaches its full yield capacity as per design. Many of studies were carried out in last few decades on the subject of seismic and non-seismic performance of beam column joints regarding shear and moment handling mechanism and strength of the joints. Beam column joint design is considered to be an intricate and exigent job for structural engineers and efficient design of R.C.C seismic moment resisting frames is critical to safety of structure. Joint size entirely depends upon size of members of frame; joints are expected to handle complex combinations of loads in addition to those considered at time of design. Special considerations should be given to design and detailing of joints subjected to seismic forces. Chances of development of plastic hinge in columns increases when the frames are inappropriately designed. This is undesirable because (a) collapse mechanism linked with hinges in columns has a lower ultimate load; (b) absorption of energy by plastic hinges contained by column is less due to arrangement of reinforcement and load over the column. Strong column weak beam approach can be used in such cases to overcome this problem. As per fundamentals of this approach adjoining elements are designed in such a manner that column and joints acts elastically under the action of external seismic and other lateral loads and main primary energy dissipation elements should be the plastic hinges in beams. Plastic hinges forming in transverse load resisting elements should have a considerable gap between them. This is to avoid brittle failure which would be more liable to occur due to concentration of plasticity in the interior of joint.

\section{LITERATURE SURVEY}

(Ragheed Fatehi Makki IJSTR 2014)[1] studied response and behavior Of Reinforced Concrete Beams Retrofitted By using Ferrocement jacketing technique. Results indicate that with increase in diameter of wire mesh, ultimate strength of R.C.C Beams also increases by $95 \%$ to $175 \%$ without stirrups and $69.8 \%$ to $126.4 \%$ with steel stirrups.wire mesh diameter used in study was in the range of $1.2 \mathrm{~mm}$ to $2.2 \mathrm{~mm}$.For repairing beams the change of diameter of wire mesh from $1.2 \mathrm{~mm}$ to $2.2 \mathrm{~mm}$ in study results in increase in ultimate strength from $67.5 \%$ to $125 \%$ without steel stirrups and $50.94 \%$ to $84.9 \%$ with steel stirrups.

(Patil ,ogale \& Dwivedi 2012)[2] studied the effect on beams after retrofitting with ferrocement jackets. Safe load carrying capacity of R.C.C sections observed to increase considerably. In such a condition, the material like ferrocement comes to our rescue as it is flexible to use and easy in installation. Its use in retrofitting technique is done for strength upgrading of structures (Kaushik et al, 1987)[3].

For an effective earthquake resistant design, ductility requirements are the key features to be taken into account. Due to higher ductility characterized by ferrocement its large scale use and application in retrofitting and rehabilitation of buildings damaged by earthquakes is reported by various researchers (Desia, 1999, Wasti and Erberik et al, 1998)[4]. (Ong et al 1992)[5] studied and presented data on repaired and strengthened R.C.C beams with ferrocement laminate.
Observations regarding shear connections were made using epoxy resins, adhesives, hilti bolts and Ramset nails. Performance of characteristics like ultimate strength, cracking and deflection of control beams were compared to strengthened beams. Greater stiffness and higher ultimate flexural capacities were exhibited by strengthened beams in comparison to those controlled beams.

(Jianchun Li et al 2002)[6] reported that making simple description of complex beam column junction modified with reinforcement in form of fiber reinforced plastic require comprehensive knowledge of behavior of such component and factual support from experimental data for model modification and updating. This paper involves a broad experimental work through which it investigates and presents the behavior of framed specimens of R.C.C which are designed to symbolize the beam column connection in plane frames. As an extension to earlier reported works the main focus is on facts of experimental analysis and particularly on strain analysis. Results presented by the experiments show that improved load carrying capacity and increased stiffness are achieved by incorporating hybrid FRP reinforcement with conventional reinforcement.

(Abhijit Mukherjee et al 2005)[7] studied the R.C.C beam column joint reinforcement under the influence of cyclic loading. Joint with adequate reinforcement and those with deficient bond reinforcements were casted. Application of FRP strips and FRP sheets in different configuration were done on joints. Beams were subjected to cyclic loading and axial force was applied to columns with controlled displacement. Use of dynamic actuator is done for monotonically increasing the amplitude of displacement. Hysteretic curves obtained from the testing of specimens are plotted. Energy dissipation capacities corresponding to different FRP configurations are compared. Besides that the controlled specimens after getting damaged are used for carrying out experiments on rehabilitation. The retrofitting has been carried out and specimens are compared with those controlled specimens or undamaged specimens.

(Y.A Al-Sallow et al)[8] studied the usefulness and efficiency of use of carbon fiber reinforced polymers (CFRP) sheets in repairing and retrofitting of seismically inferior external beam column joints with the aim of up gradation of shear strength and modification of structural ductility of such beam column joints. For carrying out this experiment an assembly of R.C.C beam column external joint was constructed with least favorable design parameters like insufficient shear strength of joint with negligible transverse reinforcement indicating design based on pre-seismic codes which takes considerably into account the large number of beam column junctions of existing buildings. To provide an equivalent effect of severe earthquake damage, cyclic lateral loads were applied on specimens during tests. CFRP sheets were then used to repair the damaged specimens. The specimens are further subjected to the cyclic loading as applied earlier and response behavior data of specimens was recorded. A comparison is then developed among the response histories of sample after repair and before repair. Comparison of results is done through load displacement envelops, stiffness and ductility degradation and hysteretic loops. Results showed substantial improvement in ductility and shear resistance of joints with the use of CFRP sheets. 
(Ahmad Gobarah et al 2002)[9] carried out studies and presented the data which shows that the shear failure of columns and beams forms the basis of principle cause of failure of large number of moment resisting frames in buildings. Efficient and less costly repair and retrofit techniques are needed for upgrading the shear resistance capacity of beam column joints in existing building structures. The objective of this research is to use the advance composite materials and develop the useful and effective rehabilitation techniques and schemes for R.C.C column beam junctions. A number of reinforced cement concrete beam column joints were constructed. The joints were designed to replicate less superior and non ductile detailing features as per pre-seismic codal provisions. The controlled specimens were subjected to cyclic loading. These specimens showed signs of joints shear failures at the tip of the beam. Keeping in view the shear strength up gradation of the joint, various rehabilitation schemes of fiber wrap were applied to the panel of joint. The rehabilitation techniques which were tested were proved to be successful and effective in delaying or eliminating the shear mode of failure and considerably improving the joint shear resistance. This chapter is intended to discuss research works relating to various methods and application techniques for retrofitting and of beam column joints.

\section{EXPERIMENTAL PROGRAM}

\section{A. Ferrocement}

Ferrocement is a composite material consisting of rich cement mortar matrix uniformly reinforced with one or more layers of very thin wire mesh with or without supporting skeletal steel. One of the essential components of ferrocement is wire mesh. Different types of wire meshes are available almost everywhere, they generally consist of thin wires, either woven or welded into the mesh but main requirement is that it must be easily handled and if necessary, flexible enough to be bent around sharp corners. The function of wire mesh and reinforcing rod is to provide the form and to support the mortar in its green state. In the hardened state, its function is to absorb the tensile stresses on the structure. Ferrocement is a term commonly used to describe a steel and mortar composite material. Essentially a form of reinforced concrete, it exhibits behavior so different from conventional reinforced concrete in performance, strength, and potential application that it must be classed as a completely separate material. Ferrocement can be formed into a section less than 1 inch thick, with only an only fraction of an inch of cover over the outermost mesh layer. Conventional concrete is inch or so of concrete cover over the outermost steel rods. Ferrocement reinforcement can be assembled over a light framework into the final desired shape and mortared directly in place, even upside down, with a thick mortar paste. Conventional concrete must be cast into forms. These fairly simple differences lead to other, more remarkable differences. Thin panels of ferrocement can be designed to levels of strain or deformation, with complete structural integrity and water tightness, far beyond limits that render conventional concrete useless .Ease of fabrication makes it possible to form compound shapes with simple techniques; with inexpensive material ; and , if necessary ,unskilled (but supervised) labour. Ferrocement is a versatile construction material and confidence in the material

is building up resulting in its wider application especially in developing countries such as for housing, sanitation, agriculture, fisheries, water resources, water transportation freshwater and marine environment, biogas structure, repair and strengthening of older structures, and others. Considered to be an extension of reinforced concrete, ferrocement has relatively better mechanical properties and durability than ordinary reinforced concrete. Within certain loading limits, it behaves as a homogeneous elastic material and these limits are wider than for normal reinforced concrete reinforced concrete. The uniform distribution and high surface area to volume ratio of its reinforced results in better crack arrest mechanism i.e. the propagation of cracks are arrested resulting in high tensile strength the material.

\section{B. Materials used in program}

Materials used in construction of beam column joints include cement, fine aggregates, coarse aggregates and steel reinforcing bars. These beam column joints are first tested and then retrofitting is done using ferrocement jacketing. HYSD reinforcing bars of $12 \mathrm{~mm}$ diameter and $8 \mathrm{~mm}$ diameter are used as reinforcement in specimens while casting. $1.2 \mathrm{~mm}$ diameter steel wire mesh is used in constructing ferrocement jacket. Mesh used is hexagonal shaped having one of the dimensions of hexagon as 10mm.Portland pozzolana cement conforming to IS 1489:1991 (Part -1)[11] is used. Indian standard concrete mix design code is used to design concrete mix of grade M-30 for constructing specimen. Concrete mix is prepared using a water cement ratio of 0.45 . After testing the cube specimens the strength at 7 days was observed as $33.33 \mathrm{~N} / \mathrm{mm}^{2}$ and strength at 28 days was observed as 23.26 $\mathrm{N} / \mathrm{mm}^{2}$. Cement to sand ratio was kept as of $1: 1.5$ by weight. This ratio in any case should not exceed 1:3 in any case. Large sand content requires larger amount of water to maintain same level of workability. Fineness modulus of sand and water cement ratio to be required was calculated from trial batches for achieving strong and dense mix and enabling it to infiltrate the 1:3 mortar was used for plastering the wire mesh.

\section{C.Design and detailing of beam column joint specimens}

Total six numbers of beam column joint specimens were constructed. Fe 500 grade steel and M-30 grade concrete was used. Joint specimen consisted of two columns of rectangular cross section $200 \mathrm{~mm} \times 150 \mathrm{~mm}$. Cross sectional dimensions of beams are $200 \mathrm{~mm} \times 200 \mathrm{~mm}$. Beam at its both ends is casted monolithically with caps of both columns. Clear span of beam is $300 \mathrm{~mm}$. inner face vertical bars of columns consists of $12 \mathrm{~mm}$ diameter bars which are curtailed at length equal to development length from vertical inner face of column near the compression face of beam. These bars terminate somewhere in the outer face of column. Outer face vertical reinforcement of column in form of $8 \mathrm{~mm}$ diameter bars run through full height of column up to compression face of beam then run as top anchor bar of beam and again form outer face vertical reinforcement of columns with terminating at any location discussed above .Provision of detailing and development length is according to IS 13920[12]. Main tensile reinforcement of beam is in form of two $12 \mathrm{~mm}$ diameter bars. These bars terminate in 


\section{Effect of Retrofitting on Beam-Column Joints}

compression zone as per IS 13920.Ties in column are in form of $8 \mathrm{~mm}$ diameter bars bent in rectangular shape of size $150 \mathrm{~mm} \times 100 \mathrm{~mm}$. Stirrups provided in beam are $8 \mathrm{~mm}$ diameter bars bent in square shape of size $150 \mathrm{~mm} X$ $150 \mathrm{~mm}$.details of reinforcement of column beam joint are shown in Figure-1.Outer face to outer face length of beam is $600 \mathrm{~mm}$ whereas clear span is $300 \mathrm{~mm}$.
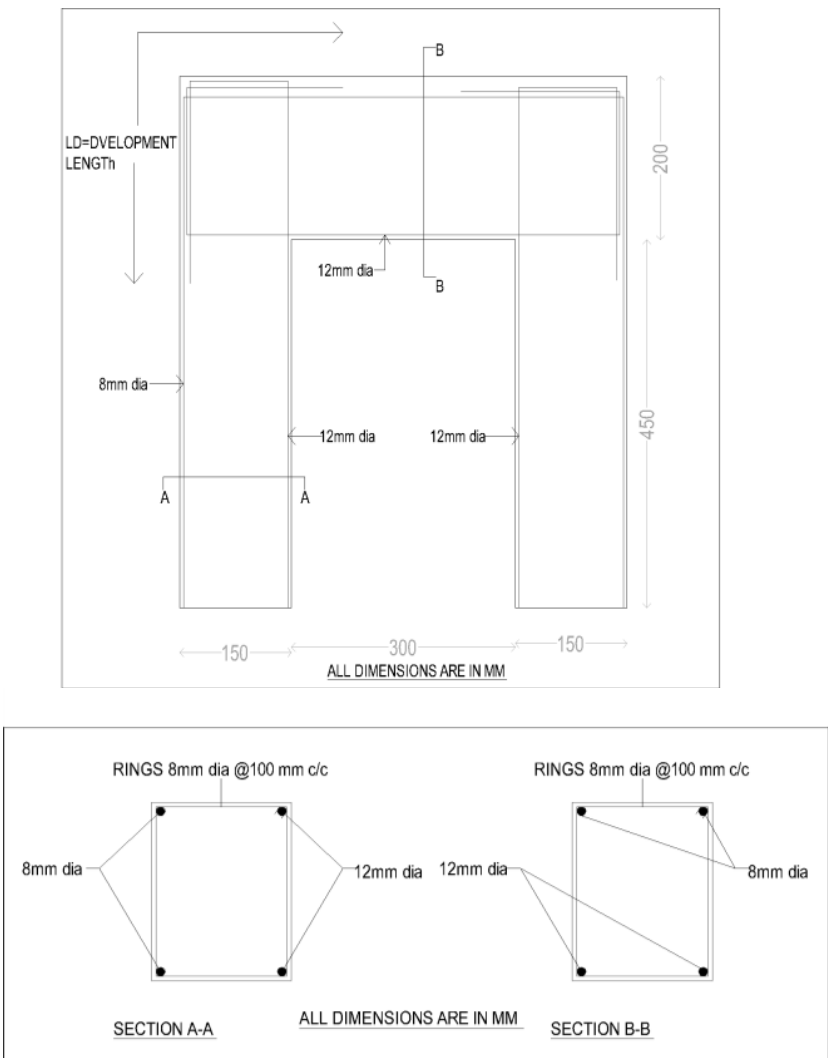

Figure-1 Details of reinforcement of column beam joint

\section{Construction of specimens}

Construction of all joint is carried at once from same lot of concrete. Casting of specimens was done by installing shuttering in horizontal position. Shuttering is in form of steel base plates over which wooden plies are installed to form moulds of specimen size and shape to form moulds for receiving reinforcement and concrete. Concrete was filled in moulds and compaction with help of vibrators was done as shown in Figure-2. After removing shuttering, specimens were cured for 28 days by immersing in curing tank. Before testing, specimens are taken out of curing tank. Before testing, specimens are taken out of curing tank and wiped off. Cube moulds are filled with concrete to find strength in laboratory.
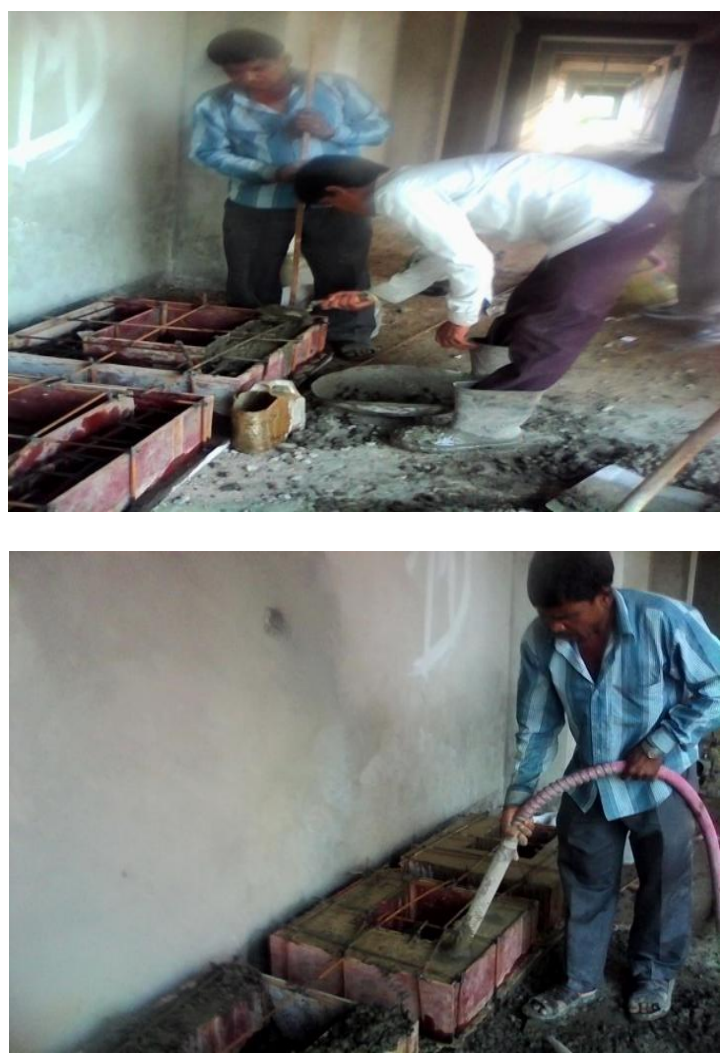

Figure-2 Casting procedure of specimens

\section{E. Testing procedure and arrangement}

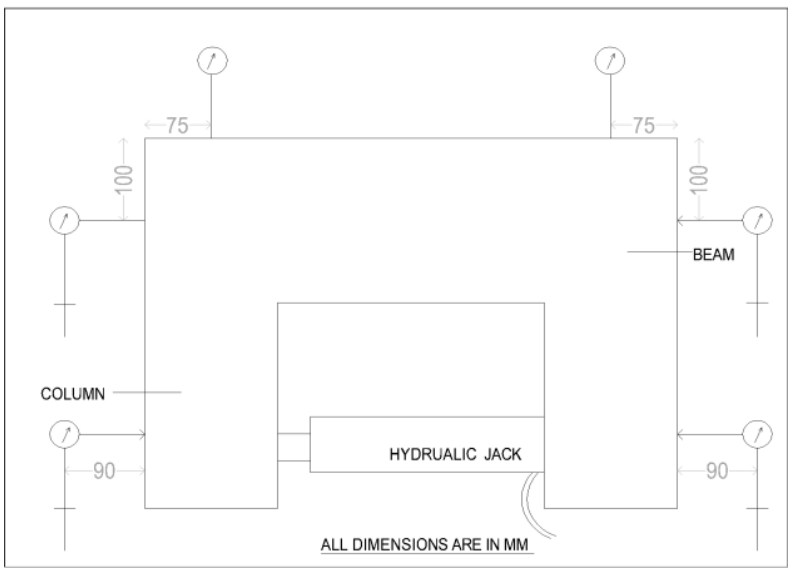

Six number dial gauges are placed at predefined positions as shown in Figure-3 for measuring deflection of specimen at various points. Two dial gauges are placed on either side near column base at outer vertical faces of columns $90 \mathrm{~mm}$ from column base along longitudinal axis of column. Other two dial gauges are placed on either side of outer faces of beam. These two gauges are placed at centre point of depth of beam i.e $75 \mathrm{~mm}$ from top compression face. Remaining two dial gauges are placed on top face of beam at $75 \mathrm{~mm}$ from end edge of beam. 


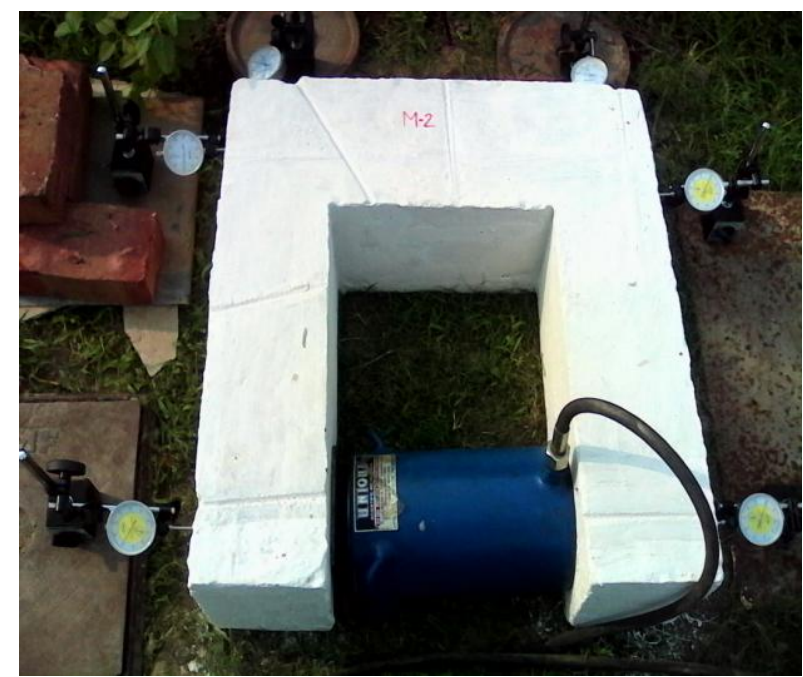

Figure-3 Hydraulic jack \& dial gauge arrangement installed for testing the beam column joint specimens

\section{F. Testing of controlled specimens}

Hydraulic jack was installed between two columns near the column base. Hydraulic pressure was applied which tends the telescopic ram to move outwards exerting the horizontal thrust on column. Deflection values at corresponding load levels were noted. Also crack pattern was observed. Out of the total six specimens, two specimens were subjected to $100 \%$ damage, the other two specimens were subjected to $75 \%$ damage of ultimate failure load. The last two specimens were subjected to $50 \%$ of ultimate failure load value. The specimens were then retrofitted.

\section{G. Retrofitting and testing of retrofitted specimens}

Specimen was properly to clean fine particles from cracks developed as a result of damage. After that chicken wire mesh was wrapped around whole specimen. Further, cement slurry was applied. Process of retrofit is shown in Figure-4. After that 1:3 cement plaster $20 \mathrm{~mm}$ thick was applied. Specimens were again cured for 14 days.

After that, retrofitted specimens were tested as shown in Figure-5. The specimens which were earlier subjected to $100 \%$ damage are again loaded to same stress levels. And the other specimens that were subjected to $75 \%$ and $50 \%$ damage prior to retrofit are again subjected to same level of stresses.

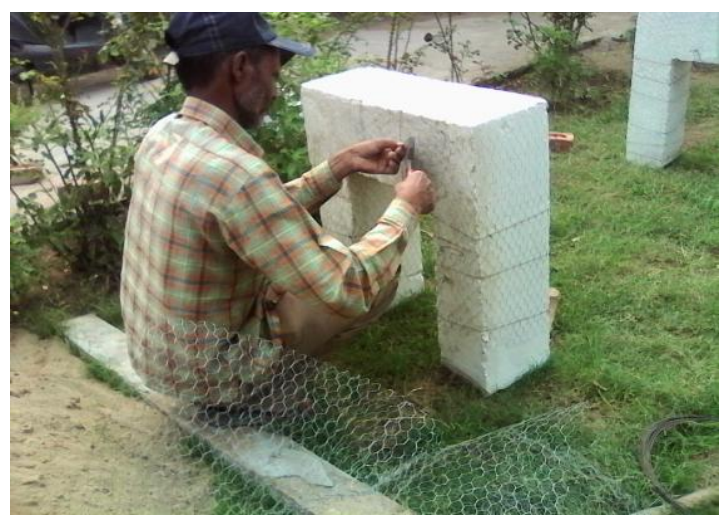

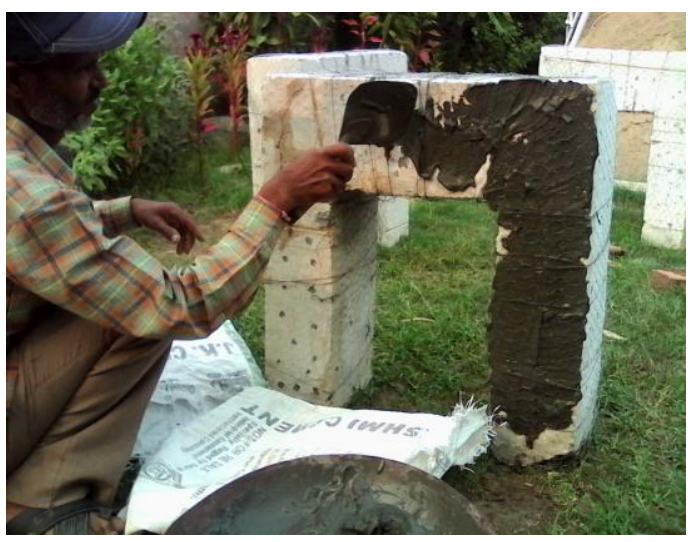

Figure-4 Procedure of retrofitting

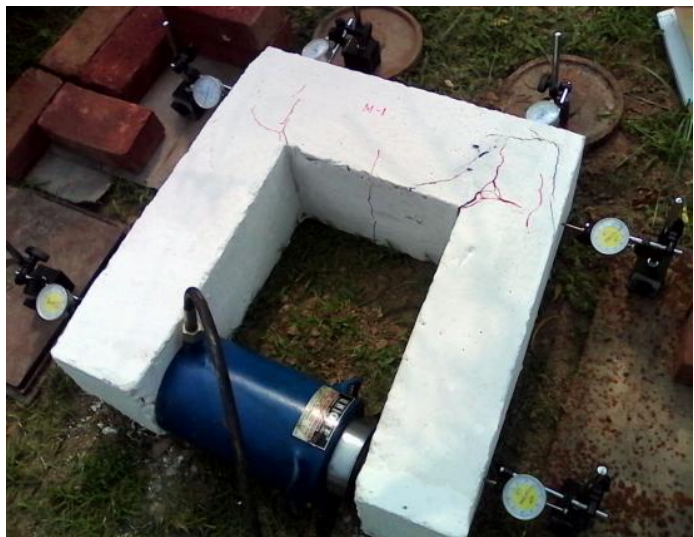

Figure-5 Testing of retrofitted beam column joint

\section{RESULTS AND DISCUSSIONS}

Aim of this experimental study was to investigate the variation of deflection of retrofitted beam column joints in comparison to controlled specimens.

A. Joints subjected to ultimate failure load $(100 \%$

Damage)

Yield load and ultimate load of specimen were observed as $24 \mathrm{KN}$ and $26.58 \mathrm{KN}$ respectively. Whereas yield load and ultimate load for controlled specimens were $20 \mathrm{KN}$ and $22.12 \mathrm{KN}$ respectively. Deflection at ultimate loads for controlled specimens was $20.45 \mathrm{~mm}$ whereas deflection of retrofitted specimen at ultimate load was $17.83 \mathrm{~mm}$. Decrease in percentage deflection in specimens after retrofitting was observed as $12.43 \%$.This is shown in graph-1.

\section{B. Joints subjected to $75 \%$ of ultimate failure load}

For specimens subjected to $75 \%$ of ultimate load, corresponding deflection for controlled specimen was $6.47 \mathrm{~mm}$. Whereas retrofitted specimens stressed to $75 \%$ stress levels showed the deflection of $3.82 \mathrm{~mm}$.

$40.95 \%$ decrease in deflection was observed for retrofitted specimens in comparison to controlled specimens. Graph-2 shows deflection comparison of controlled and retrofitted specimen.

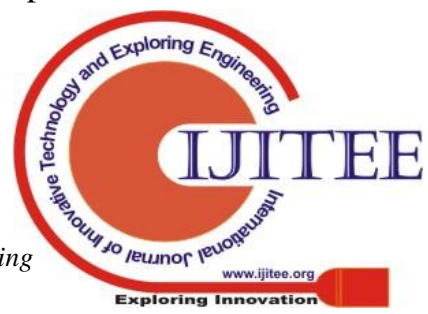




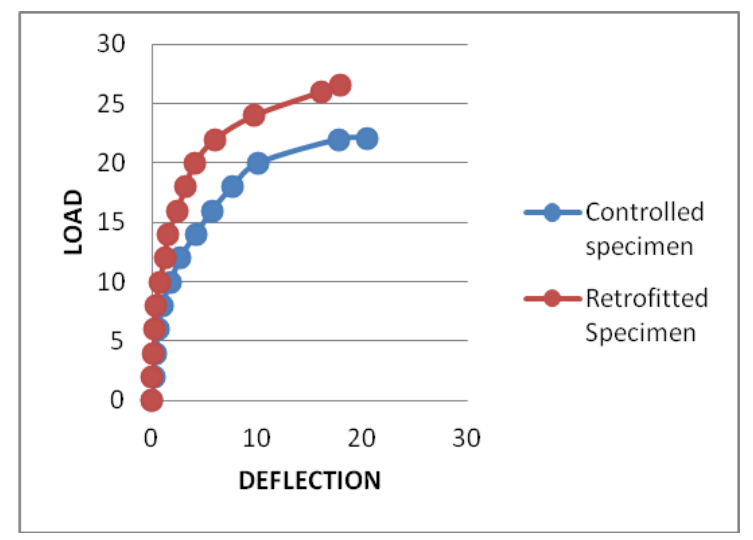

Graph-1 Load deflection curve for Controlled \& Retrofitted specimen (100\% Damage)

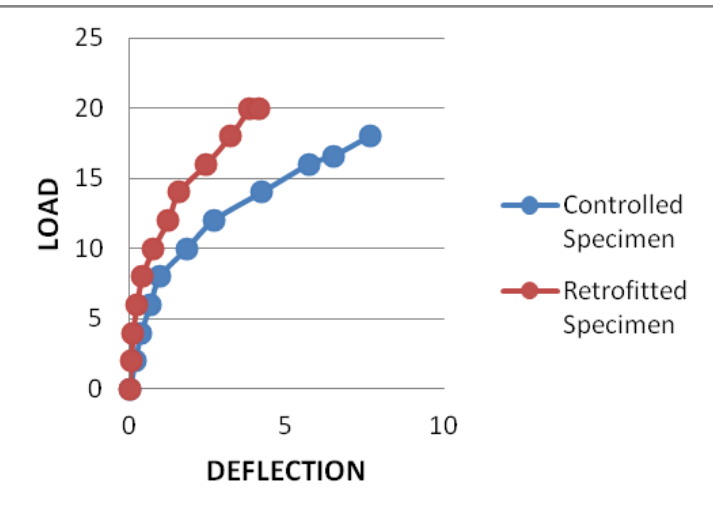

Graph-2 Load deflection curve for Controlled \& Retrofitted specimen (75\% Damage)

C. Joints subjected to $50 \%$ of ultimate failure load Controlled specimens stressed to $50 \%$ stress showed a deflection of $2.67 \mathrm{~mm}$. After retrofitting when these specimens were tested, they showed deflection of $1.56 \mathrm{~mm}$. After testing retrofitted specimens $36.77 \%$ decrease in deflection was observed in comparison to controlled specimens.Graph-3 shows deflection comparison for specimens stressed to $50 \%$ of ultimate failure load.

The results presented above for retrofitted specimens tested at varying levels of stresses show that the process of retrofitting by chicken wire mesh increases stiffness of joints which are vulnerable to fail by seismic activity.

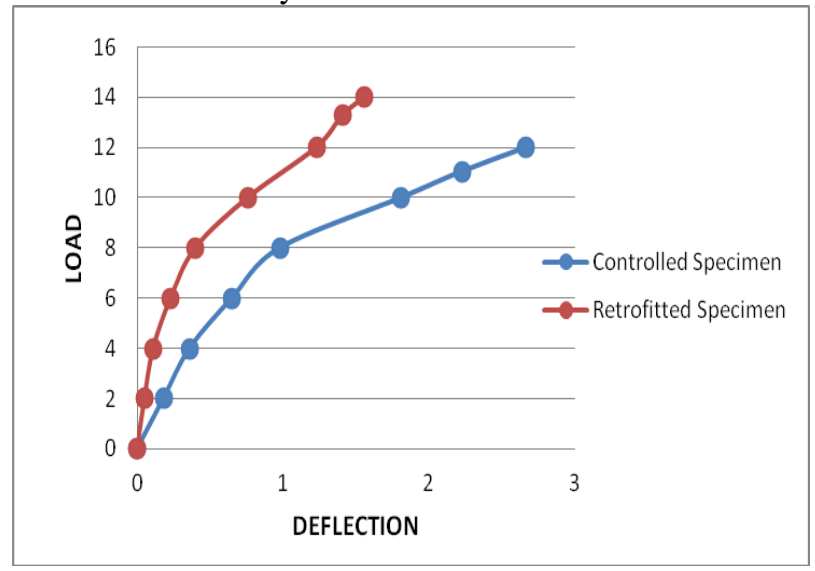

Graph- 3 Load deflection curve for Controlled \& Retrofitted specimen (50\% Damage)

\section{CONCLUSION}

1. For specimens subjected to $100 \%$ damage, $12.43 \%$ decrease in deflection is observed for retrofitted specimens in comparison to controlled specimens.

2. For specimens subjected to $75 \%$ of ultimate loads, $40.95 \%$ decrease in deflection was observed for retrofitted specimens in comparison to controlled specimens.

3. Retrofitted specimens which were stressed to $50 \%$ of ultimate loads had shown $36.77 \%$ decrease in deflection in comparison to controlled specimens.

\section{REFERENCES}

[1] Makki Ragheed Fatehi "Response of Reinforced Concrete Beams Retrofitted by Ferrocement" International journal of Scientific and Technology Research, Vol 3, Issue 9, Sep 2014, ISSN 2277-8616.

[2] S Patil Sandesh, Ogale R.A, Dwivedi Arun Kumar, "Performance of Chicken Mesh on Strength of Beams Retrofitted using Ferrocement Jackets" Journal of Engineering Vol.2, Issue 7, July 2012, PP01-10

[3] Kaushik, S.K; Gupta.V.K.and Rahman.M.K. "Efficiency of mesh overlays of ferrocement elements" Journal of ferrocement 17(4) 1987.

[4] Desia, R., "Field Shake Test Programme at Latur, Western India," News letter,Earthquake Hazard Centre, New Zealand, V. 3, No.2, pp. 4-5 (1999).

[5] Ong, K.C.G., Paramasivam, P., and Lim, C.T.T.," Flexural strengthening of reinforced concrete beams using ferrocement laminates". Journal of ferrocement, Vol 22, No 4, pp 331-342 (1992).

[6] Desayi, P., and El-Kholy, S.A., "Deflection and cracking behaviour of lightweight fiber reinforced ferrocement", Journal of Ferrocement, Vol. 22, No2, pp 135-150 (1992).I

[7] Mukherjee, Abhijit, Joshi, Mangesh, "FRPC reinforced concrete beam-column joints under cyclic excitation". Composite Structures 70 (2005) 185-199.

[8] Al-Salloum, Y.A., Alsayed, S. H., Almusallam, T. H. \& Siddiqui, N. A "seismic performance of shear deficient exterior rc beam-column joints repaired using CFRP composite

[9] Ahmad Gobarah et al 2002, "Seismic rehabilitation of beam-column joints using FRP laminates". (2002)

[10] Wasti, S.T., Erberik, M.A., Sucuoglu, H.., and Kaur, C., "Studies on Strengthening of Rural Structures Damaged in the 1995 Dinar Earthquakes," Proceedings of the Eleventh European Conference on Earthquake Engineering, Paris, France (1998).

[11] IS 1489:1991 (Part -1) Portland-Pozzolana Cement Specifications.

[12] IS 13920 Ductile Detailing Of Reinforced Concrete Structures Subjected To Seismic Forces -Code Of Practice.

\section{AUTHORS PROFILE}

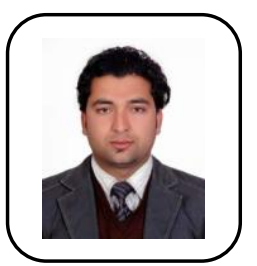

DEEPENDRA PRASAD BHATTA received his B.Tech degree in civil engineering in 2011 from Nepal engineering college (Pokhara University),Nepal. M.Tech in construction management from Nepal engineering college (Pokhara University) in 2016. He is Phd Research Scholar in the Civil Engineering Department at RIMT University, Punjab. Presently, he is working as Managing Director, D. B. Multi Engineering Consultant P. Ltd and principal of Oxford Advance Engineering College , Kathmandu, Nepal.

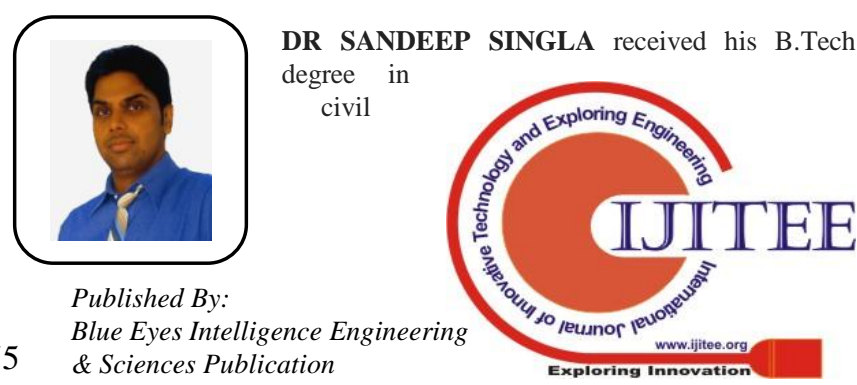


engineering in 2001 from Punjab Technical University, Jalandhar M.Tech from Thapar Institute of Engineering \&Technology, Patiala in 2004 \& PhD degree from National Institute of Technology (NIT) Kurukshetra in 2018. Presently, he is working as Professor \& Head in Department of Civil Engineering, RIMT University, Punjab, India. He has published more than 60 papers in national and international journals/conferences. He has guided more than 30 M.Tech thesis. Besides being member of board of studies in various universities, he is a life member of ISTE and also member of IEI. His research interests include environmental engineering, waste management, concrete technology, artificial intelligence, remote sensing and GIS.

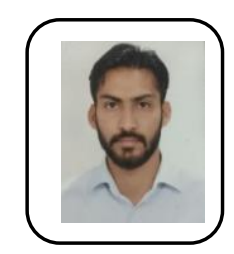

MANISH KAUSHAL received his B-Tech degree in civil engineering in 2011 from Punjab Technical University, Jalandhar, M-Tech from Punjab Technical University, Jalandhar in 2015. Presently, he is working as Assistant Professor in Department of Civil Engineering RIMT University, Punjab, India. He has guided more than $10 \mathrm{M}$.Tech thesis.

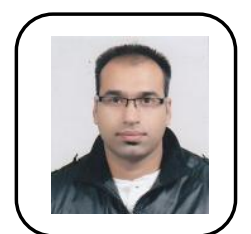

ANUJ SACHAR received his B-Tech degree in civil engineering in 2008 from Punjab Technical University, Jalandhar, M-Tech from RIMT University. Presently, he is working as Assistant Professor in Department of Civil Engineering RIMT University, Punjab, India. 